\title{
Correction to: Clinical and microbiological effects of non-surgical periodontal treatment in individuals with rheumatoid arthritis: a controlled clinical trial
}

\author{
Marcela F. Moura ${ }^{1} \cdot$ Luís O. M. Cota $^{1} \cdot$ Tarcília A. Silva $^{1} \cdot$ Sheila C. Cortelli ${ }^{2} \cdot$ Gilda A. Ferreira $^{3} \cdot$ Marina M. López $^{1}$. \\ José R. Cortelli ${ }^{2} \cdot$ Fernando O. Costa ${ }^{1}$ (1)
}

Published online: 9 December 2020

(c) The Society of The Nippon Dental University 2020

\section{Correction to: Odontology \\ https://doi.org/10.1007/s10266-020-00566-0}

In the original publication of the article, the Table 3 was published incorrectly. The correct Table 3 is provided below.

The original article was corrected.

Publisher's Note Springer Nature remains neutral with regard to jurisdictional claims in published maps and institutional affiliations.

The original article can be found online at https://doi.org/10.1007/ s10266-020-00566-0.

Fernando O. Costa

focperio@uol.com.br

1 Department of Dental Clinics, Oral Pathology, and Oral

Surgery, Department of Periodontology, Faculty

of Dentistry, Federal University of Minas Gerais,

Antônio Carlos Avenue, 6627, Pampulha, PO Box 359,

Belo Horizonte, Minas Gerais 31270-901, Brazil

2 Faculty of Dentistry, University of Taubaté, São Paulo, Brazil

3 Faculty of Medicine Federal, University of Minas Gerais, Belo Horizonte, Minas Gerais, Brazil 
Table 3 Microbiological findings of + PE + RA and + PE - RA groups at T1 and T2

\begin{tabular}{|c|c|c|c|c|c|c|c|}
\hline \multirow[t]{2}{*}{ Bactéria $\left(\times 10^{3}\right)$ mean $\pm \mathrm{SD}$} & \multicolumn{3}{|c|}{$+\mathrm{RA}+\mathrm{PE}(N=24)$} & \multicolumn{4}{|c|}{$+\mathrm{PE}-\mathrm{RA}(N=30)$} \\
\hline & $\mathrm{T} 1$ & $\mathrm{~T} 2$ & $p^{*}$ & $\mathrm{~T} 1$ & $\mathrm{~T} 2$ & $p^{*}$ & Intergroup $p^{\dagger}$ \\
\hline A. actinomycetemcomitans & $92.07 \pm 20.88$ & $71.02 \pm 23.04$ & 0.001 & $82.92 \pm 11.26$ & $57.42 \pm 15.42$ & $<0.001$ & 0.020 \\
\hline P. gingivalis & $17.89 \pm 4.76$ & $11.07 \pm 10.98$ & 0.008 & $20.30 \pm 16.91$ & $14.1 \pm 10.92$ & 0.021 & $<0.001$ \\
\hline T. denticola & $19.21 \pm 6.07$ & $6.61 \pm 2.34$ & $<0.001$ & $16.78 \pm 5.25$ & $7.89 \pm 4.21$ & $<0.001$ & 0.35 \\
\hline T. forsythia & $59.51 \pm 19.11$ & $26.43 \pm 9.41$ & 0.001 & $51.47 \pm 20.19$ & $29.42 \pm 8.89$ & $<0.001$ & 0.81 \\
\hline
\end{tabular}

*Wilcoxon test

${ }^{\dagger}$ Mann-Whitney test 